\title{
Glomus intraradices Attenuates the Negative Effect of Low Pi Supply on Photosynthesis and Growth of Papaya Maradol Plants
}

\author{
Nava-Gutiérrez Yolanda, ${ }^{1,2}$ Ronald Ferrera-Cerrato, ${ }^{3}$ and Jorge M. Santamaría ${ }^{1}$ \\ ${ }^{1}$ Laboratorio de Fisiología Vegetal Molecular, Centro de Investigación Científica de Yucatán, Calle 43 No. 130, \\ Colonia Chuburná de Hidalgo, Mérida, YUC, México 97200, Mexico \\ ${ }^{2}$ Laboratorio de Micorrizas, Centro de Investigación en Ciencias Biológicas (CICB), Universidad Autónoma de Tlaxcala, \\ Ixtacuixtla, TLAX, México 90000, Mexico \\ ${ }^{3}$ Área de Microbiología, Especialidad de Edafología, Instituto de Recursos Naturales, Colegio de Postgraduados Campus, \\ Montecillo, MEX, México 56230, Mexico
}

Correspondence should be addressed to Jorge M. Santamaría, jorgesm@cicy.mx

Received 1 August 2011; Accepted 13 September 2011

Academic Editor: Kang Chong

Copyright (c) 2012 Nava-Gutiérrez Yolanda et al. This is an open access article distributed under the Creative Commons Attribution License, which permits unrestricted use, distribution, and reproduction in any medium, provided the original work is properly cited.

\begin{abstract}
Low inorganic phosphorus ( $\mathrm{Pi}$ ) supply limits the photosynthetic process and hence plants growth and development. Contradictory reports exist in the literature on whether mycorrhyzal association can attenuate the negative effects of low Pi supply on photosynthesis and growth. In the present paper, the effect that low Pi supply may have on photosynthesis and growth of papaya Maradol plants was evaluated in intact plants and in those inoculated with two different strains of the arbuscular mycorrhizal fungi Glomus intraradices. Plant growth was significantly reduced as the Pi supply decreased. However, inoculation with any strain of G. intraradices was able to attenuate such effect. Without Pi in the nutrient solution, the mycorrhizal plants had on average 6.1 times and 7.5 higher photosynthesis than non mycorrhizal plants. The chlorophyll fluorescence values were significantly higher in mycorrhizal than in non-mycorrhizal plants. These results could be associated to an increased ability of mycorhyzal plants to take up Pi from the substrate, as they had higher Pi content than non-mycorrhizal plants. A high correlation was found between internal Pi content and plant biomass. The lower correlation between Pi content and photosynthesis, suggests that some photosynthates could had been used to maintain the symbiosis.
\end{abstract}

\section{Introduction}

The scarcity of nutrients is a factor that limits physiological processes in plants, including photosynthesis, their growth, and development [1]. Phosphorus (P) deficiency normally reduces the root system development and plant establishment because it has an important role in cell division, growth, photosynthesis $(P n)$, respiration, energy storage, and transfer [2-4]. So that, in many agricultural systems, it is necessary to supply $\mathrm{P}$ in order to have good productivity [5].

When plants grow with nutrient scarcity, some of them are capable of modifying their root architecture, to exude organic acids, or to establish associations with some beneficial organisms as strategies to compensate for the low concentration of nutrient in the substrate. Among the beneficial organisms for plants, the arbuscular mycorrhizal (AM) fungi have a very important role in plant nutrition
$[6,7]$. It is through AM association that plants increase their capacity to take up organic phosphorus ( $\mathrm{Pi}$ ) from the soil solution $[8-10]$ that normally translates into better growth than that of non-AM plants [11, 12].

Nevertheless, it has been reported that AM association could be more or less beneficial to the plant growth depending on the plant species and the AM fungi species [8]. In commercial papaya varieties Sunrise and Tainung, the inoculation with Gigaspora margarita induced higher production of dry matter than with Glomus clarum, growing under similar conditions [13].

Most of the studies on the role of the AM association on plants behavior are undertaken using soil [13] or a mix of inert materials-soil $[11,14,15]$ with different chemical properties in every case, which is a factor that can modify the Pi availability for the plants. In order to control the 
availability of nutrients, the present research was made in a hydroponics system under greenhouse conditions, focusing on the effect of colonisation with two strains of Gloms intraradices on the growth and $P n$ of papaya Maradol, growing with low availability of Pi in Hoagland's solution (HS).

\section{Materials and Methods}

2.1. Plants, AM Fungi, and Growing Conditions. Seeds of papaya Maradol (Carica papaya var. Maradol, Carisem) were germinated in wet chambers in darkness at $35^{\circ} \mathrm{C} \pm 3^{\circ} \mathrm{C}$. After that, they were grown in nurseries for 15-18 days until the plants had three to four leaves. Then, plants were transplanted into single pots (black nursery bags of $35 \times$ 25 centimeters) which were previously filled with agrolite, a sterile and, inert substrate, chemically stable in neutral and acid $\mathrm{pH}$. At all times, the experiment was maintained under greenhouse conditions, with $35^{\circ} \mathrm{C}$ temperature, 55\% relative humidity, and a photosynthetic photon flow density of around $300 \mu \mathrm{mol} \mathrm{m} \mathrm{m}^{-2} \mathrm{~s}^{-1}$.

The inoculants used were two strains of the AM fungi Gloms intraradices from different origin: (1) a commercial strain Endo-Rhyza (+Mic1), that consists in spores immersed in vermiculite (2) a noncommercial strain (+Mic2), isolated and propagated in the Microbiology Area, Natural Resources, Postgraduates College, Montecillo, Mexico, consisting of spores and little segments of colonized roots in a soil-tezontle mix used as support.

When the plants were transplanted to single pots, each plant was inoculated with approximately 160 spores of each AM fungi strain, and the nonmycorrhizal and control groups were supplied with the same support from the noncommercial strain inoculant, previously sterilized. After that, in order to maintain all plants with the same pretreatment supply of $\mathrm{Pi}$ in solution and to stimulate AM colonization, all plants were supplied with $200 \mathrm{~mL}$ of low Pi $(0.3 \mathrm{mM})$ Hoagland solution (HS) [16] twice a week and $250 \mathrm{~mL}$ of distilled water once a week for five weeks. At the end of these five weeks the AM colonization was verified taking a sample from the roots of five inoculated plants.

Then, the different $\mathrm{Pi}$ concentration treatments were started, by supplying modified HS containing the various $\mathrm{Pi}$ concentrations $(0,0.3,0.6 \mathrm{mM})$. The $\mathrm{pH}$ was adjusted to 6.7 , and the necessary amount of ammonium nitrate $(0.040 \mathrm{~g}$, $0.028 \mathrm{~g}$ y $0.016 \mathrm{~g}$, resp.) was added to HS in order to maintain the $\mathrm{N}$ concentration in each case.

The experiment included nine treatments by combining three $\mathrm{Pi}$ concentrations $(0,0.3$, and $0.6 \mathrm{mM})$ and three AM conditions (+Mic1, +Mic2, and without inoculation, denoted as -Mic). Every treatment had five plants (as experimental units). The control was a papaya Maradol group without AM fungi supplied with HS without modification (Pi concentration of $1.0 \mathrm{mM}$ ).

Data from $P n$ and $\mathrm{F}_{\mathrm{V}} / \mathrm{F}_{\mathrm{M}}$ were taken after the presence of AM structures was verified (week five) in the roots, at weeks seven, nine, and ten (weeks two, four, and five after the treatments were initiated). Growth parameters, leaves $\mathrm{P}$ content and the percentage of AM colonization, were taken only at week ten.

2.2. Growth Measurements. The stem diameter was measured two centimeters from the base to the apex. The plants height was measured from the base to the apex of the stem. Dry weight was determined dividing each plant into shoot and root before they were oven-dried at $70^{\circ} \mathrm{C}$ to constant weight in order to obtain shoot, root, and total dry weight (DW).

2.3. Photosynthesis and $F_{V} / F_{M}$ Measurements. Pn was evaluated as $\mathrm{CO}_{2}$ assimilation, using the third and fourth leaves from the apex to the base of the stem. It was measured between 11 and 13:30 hours, with an infrared gas analyzer (IRGA) LICOR model LI-6200. $\mathrm{F}_{\mathrm{V}} / \mathrm{F}_{\mathrm{M}}$ data were taken on the same leaves that were used to measure photosynthesis after they were preacclimated to darkness for 30 minutes. A Plant Efficiency Analyzer (PEA, Hansatech Instruments Ltd., Kings Lynn, UK) was used set at 70\% for two seconds.

2.4. Phosphorus Measurements. Leaves $\mathrm{P}$ content measurements were carried out by digesting the plant material with nitric acid at $80^{\circ} \mathrm{C}$ [17]. The measurements were carried out using an optical emission spectrometer inductively coupled to plasma (OES-ICP), Perkin Elmer 400, at $253.4 \mathrm{~nm}$.

2.5. Arbuscular Mycorrhizal Colonization. To estimate the AM colonization, the roots were stained with trypan blue [18]. A total of 20 fragments of stained roots (about $1 \mathrm{~cm}$ long) for each treatment were mounted on slides in lactic acid and examined with an optical microscope (10x) to ascertain the presence of AM structures. Colonization percentage was calculated by

$\%$ Colonization $=\frac{\text { Number of colonized segments }}{\text { number of total segments viewed }} \times 100$.

Data are presented as the means of five replicates \pm standard deviation (SD) and were analyzed by ANOVA test using the Statgraphics 4.1 Plus program. Differences between the treatments were tested using the Tukey test at $95 \%$ of confidence $(P \leq 0.05)$.

\section{Results}

3.1. Plant Growth. Most of the growth parameters measured decreased significantly when the Pi supply in HS decreased. However, this effect was attenuated by the AM association. Stem diameter decreased as the Pi supply was reduced. However, this drop was attenuated by the AM association. When Pi was reduced from 1.0 to 0.6 and $0.3 \mathrm{mM}$, a similar reduction in stem diameter occurred in both - Mic and +Mic plants. However, when HS had no added Pi $(0 \mathrm{mM})$, stem diameter was reduced $91 \%$ in -Mic, while only $74 \%$ in + Mic1 and +Mic2 plants compared to control plants (1.0 mM) (Figure 1). 

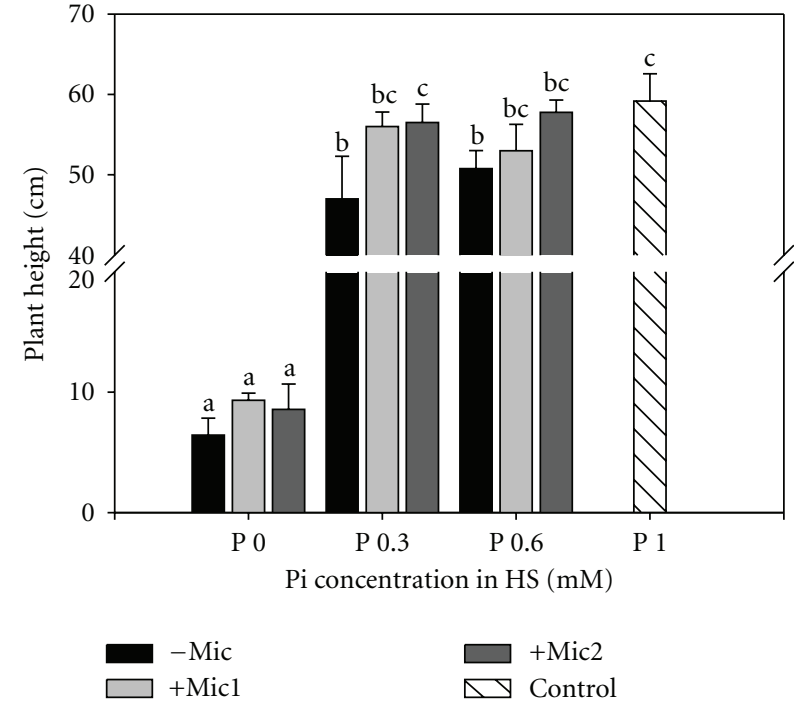

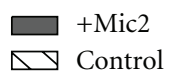

(a)
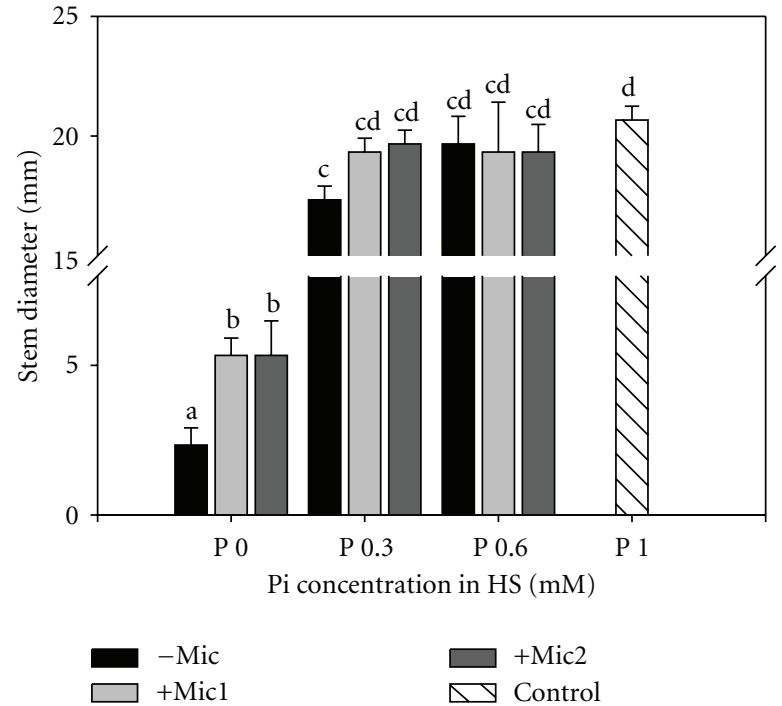

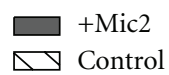

(b)

Figure 1: (a) Plant height, (b) stem diameter from papaya Maradol plants at week five of the experiment, grown with or without mycorrhiza and treated with Pi $0 \mathrm{mM}$, Pi $0.3 \mathrm{mM}$, and Pi $0.6 \mathrm{mM}$. Control plants were grown without mycorrhiza but treated with Pi $1 \mathrm{mM}$. Data are means \pm SD $(n=5)$. Values with the same letter for treatments within each Pi concentration had no statistical difference (Tukey $95 \%)$.

Shoots, roots, and total plant DW also decreased as the Pi supply was reduced and again the drop was attenuated in +Mic plants. With Pi $0.3 \mathrm{mM}$ in $\mathrm{HS}$ total DW was reduced by $20 \%$ in -Mic, while only $13 \%$ and $7 \%$ in + Mic 1 and + Mic2, respectively (Figure $2(\mathrm{~b})$ ). When grown in HS solution with no added $\mathrm{Pi}$, +Mic plants maintained 10 times higher biomass than $-\mathrm{MR}$ plants (Figure 2(a)).

3.2. Photosynthesis and $F_{V} / F_{M}$. Pn also decreased drastically as the Pi supply was reduced but MA not only was able to attenuate this effect but in some cases $P n$ in +Mic plants grown at low $\mathrm{Pi}$ showed higher $\mathrm{Pn}$ than control plants grown without Pi limitation. With Pi $0.3 \mathrm{mM}$ - Mic plants reduced their $P n$ by $63.6 \%$ while + Mic plants showed $P n$, values that were in fact higher than those in control plants grown with $1.0 \mathrm{mM}$ (Figure 3(b)). Even when no Pi was added to the HS $(0 \mathrm{mM}),+$ Mic plants maintained significantly higher $P n$ than -Mic plants (Figure 3(a)).

$\mathrm{F}_{\mathrm{V}} / \mathrm{F}_{\mathrm{M}}$ also decreased as the $\mathrm{Pi}$ supply was reduced. However at week $5, \mathrm{~F}_{\mathrm{V}} / \mathrm{F}_{\mathrm{M}}$ values remained significantly higher in +Mic plants than in -Mic plants treated with both $0.3 \mathrm{mM}$ and $0 \mathrm{mM} \mathrm{Pi}$ (Figures 4(a) and 4(b)).

3.3. Phosphorus Content. The foliar $\mathrm{P}$ content decreased as the Pi supply was reduced and again AM was able to attenuate this drop. In the case of total absence of added Pi through the HS $(0 \mathrm{mM})$, + Mic plants had significantly higher leaf $\mathrm{P}$ content than -Mic plants (Figure 5). Also, mycorrhizal plants inoculated with +Mic2 had significantly higher $\mathrm{P}$ content than the $-\mathrm{Mic}$ plants at P1 $0.6 \mathrm{mM}$, and in fact this treatment was the only one that showed laef $\mathrm{P}$ contents similar to the control plants grown with full HS containing $1 \mathrm{mM}$ Pi.
3.4. AM Colonization. No AM colonization was observed in roots of $-\mathrm{Mic}$ plants throughout the fertilization gradient. The higher AM colonization occurred in +Mic1 without Pi supply (Table 1). For both strains, AM colonization decreased as the Pi supply in HS increased. Nevertheless, this reduction was lower in AM plants inoculated with + Mic2, whose AM colonization remained two and tree times higher (with Pi $0.3 \mathrm{mM}$ and $0.6 \mathrm{mM}$, resp.) than those inoculated with +Mic1 (Table 1).

\section{Discussion}

Our results indicate that both strains of $G$. intraradices were able to attenuate the negative effect caused by low $\mathrm{Pi}$ supply on the growth (total DW) of papaya Maradol plants. One possible explanation for that could be the fact that mycorrhizal papaya Maradol plants kept more leaves than non mycorrhizal plants (data not shown) and that surely contributed to the larger shoot DW. With low Pi supply $(0.3 \mathrm{mM})$ the AM association allowed DW and plant height to remain similar to those at plants grown with higher $\mathrm{Pi}$ supply $(0.6 \mathrm{mM})$ or even those at control plants. In other study models like strawberry [19] or Medicago truncatula [15] it has also been reported that AM association reduces the stress due to the low Pi availability on plant growth. Some commercial papaya varieties like Baixinho, Tainung, Sunrise, and Improved also had greater dry matter production in association with AM fungi G. clarum and Gigaspora margarita [13]. The fact that the growth response of papaya Maradol to the AM inoculation was greater, particularly at lower concentration of $\mathrm{Pi}$, and that this response decreased at higher Pi concentration in HS, places papaya Maradol in the facultative arbuscular mycorrhizal species group. 


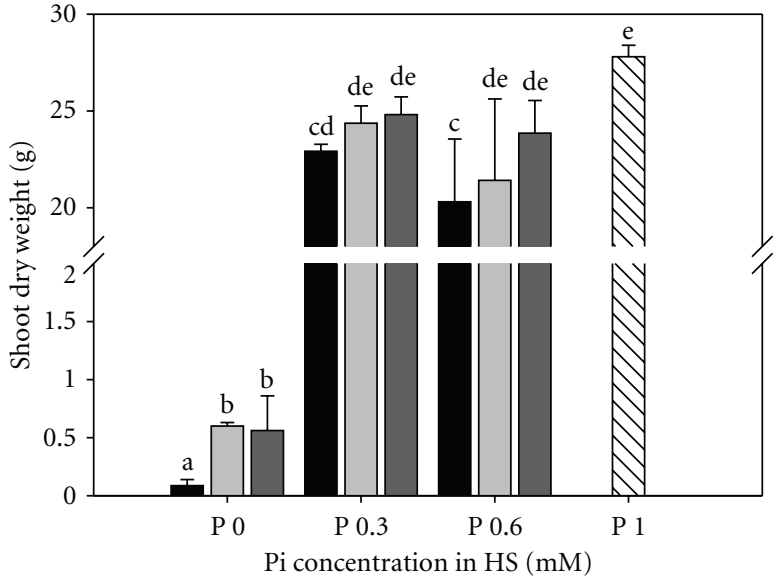

(a)

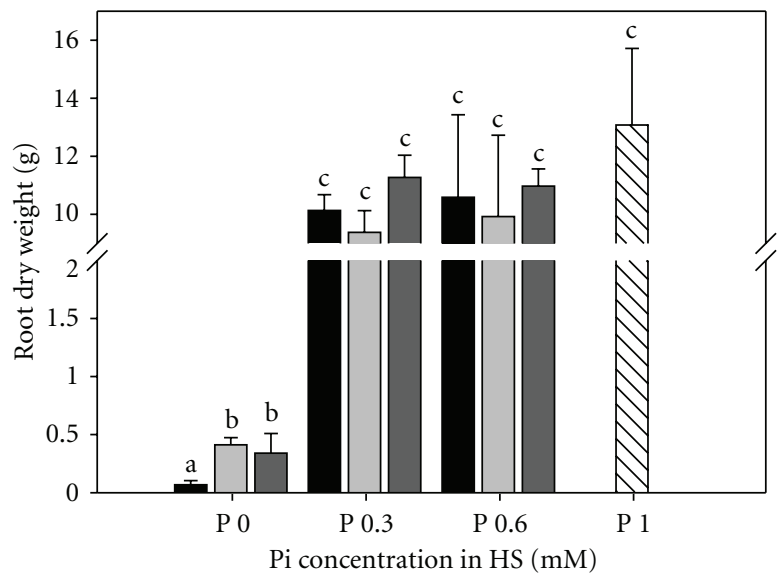

(b)

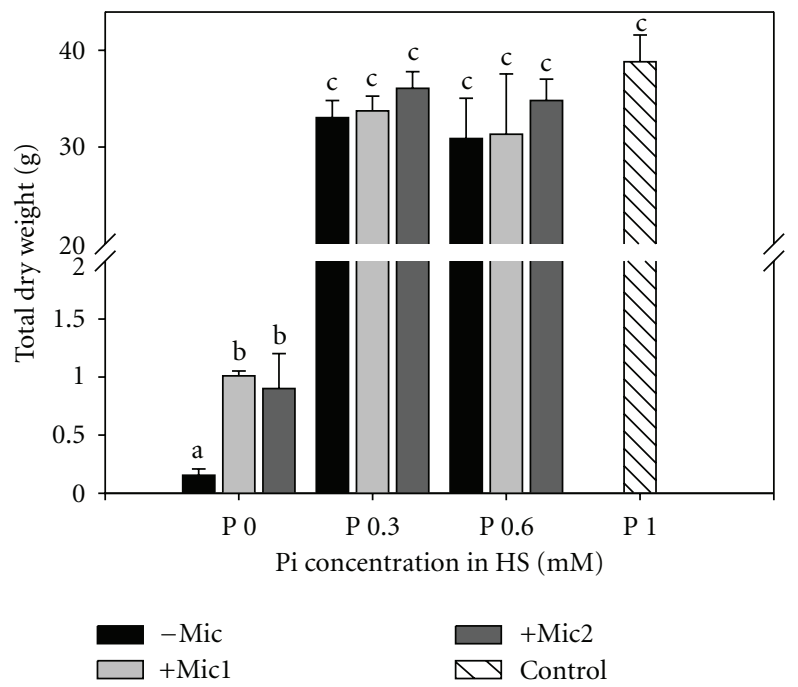

(c)

FIGURE 2: Dry weight of (a) shoots, (b) roots, (c) total plant weight from papaya Maradol plants at week five of the experiment, grown with or without mycorrhiza and treated with Pi $0 \mathrm{mM}$, Pi $0.3 \mathrm{mM}$, and Pi $0.6 \mathrm{mM}$. Control plants were grown without mycorrhiza but treated with Pi $1 \mathrm{mM}$. Data are means \pm SD $(n=5)$. Values with the same letter for treatments within each Pi concentration had no statistical difference (Tukey 95\%).

TABle 1: Arbuscular mycorrhizal colonization (\%) in papaya Maradol roots, at week five of the experiment. Data are means $(n=5)$. Values with the same letter in each strain across the Pi gradient had no statistical difference (Tukey 95\%). Values with the same uppercase letter in the row had no statistical difference.

\begin{tabular}{lcccc}
\hline \multirow{2}{*}{ Mycorrhizal condition } & \multicolumn{4}{c}{ Phosphorus $(\mathrm{mM})$} \\
& 0.0 & 0.3 & 0.6 & $1.0^{*}$ \\
\hline -Mic & 0.0 & 0.0 & 0.0 & 0.0 \\
+ Mic1 & $82.0 \mathrm{aA}$ & $16.0 \mathrm{bA}$ & $10.0 \mathrm{bA}$ & $\mathrm{nc}$ \\
+ Mic2 & $76.0 \mathrm{aA}$ & $37.0 \mathrm{bB}$ & $32.0 \mathrm{bB}$ & $\mathrm{nc}$ \\
\hline
\end{tabular}

${ }^{*}$ Total control with Pi $0 \mathrm{mM}$ where arbuscular mycorrhizal colonization was not observed; -Mic: without mycorrhiza, +Micl: commercial strain, +Mic2: noncommercial strain. $\mathrm{nc}=$ not considered.

The beneficial effect of AM association on papaya Maradol $\mathrm{CO}_{2}$ assimilation is important because it indicates that somehow the mycorrhizal plants are capable of reducing the stress on the photosynthetic apparatus caused by the low availability of Pi.

It has been reported that the negative effect of the nutrient scarcity on the development of many crops is associated with the reduction of $P n, \mathrm{~F}_{\mathrm{V}} / \mathrm{F}_{\mathrm{M}}$, and $g_{s}$, in corn [20] while in sugar beet, the low $\mathrm{Pi}$ reduced $\mathrm{CO}_{2}$ assimilation by $33 \%$ [21]. This negative effect of low Pi supply can be related to many aspects such as reduction of chlorophyll $a$ and $b$, affecting also, the PSI and PSII efficiency [20]. Furthermore, $\mathrm{Pi}$ is necessary to couple photosynthetic reactions in the dark and light phases, because of its structural and regulatory role in energy conservation and $\mathrm{CO}_{2}$ assimilation [22].

The ratio variable fluorescence over maximum fluorescence $\left(\mathrm{F}_{\mathrm{V}} / \mathrm{F}_{\mathrm{M}}\right)$ has been used as an important and easily measurable parameter of the physiological status of the photosynthetic apparatus in intact plant leaves. When plants 


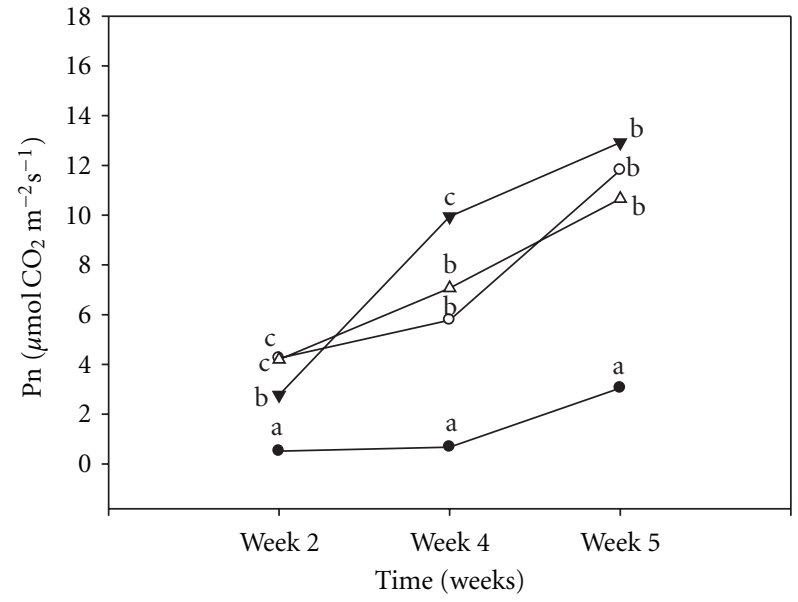

(a)

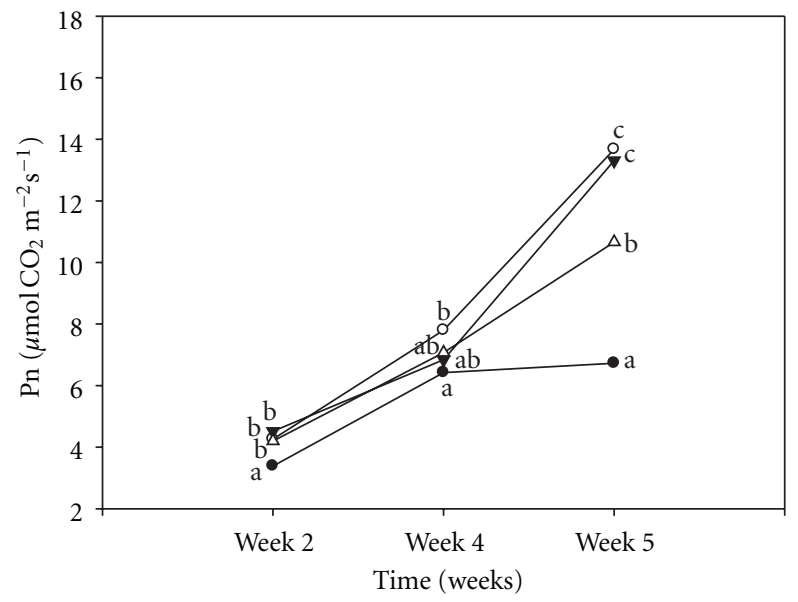

(b)

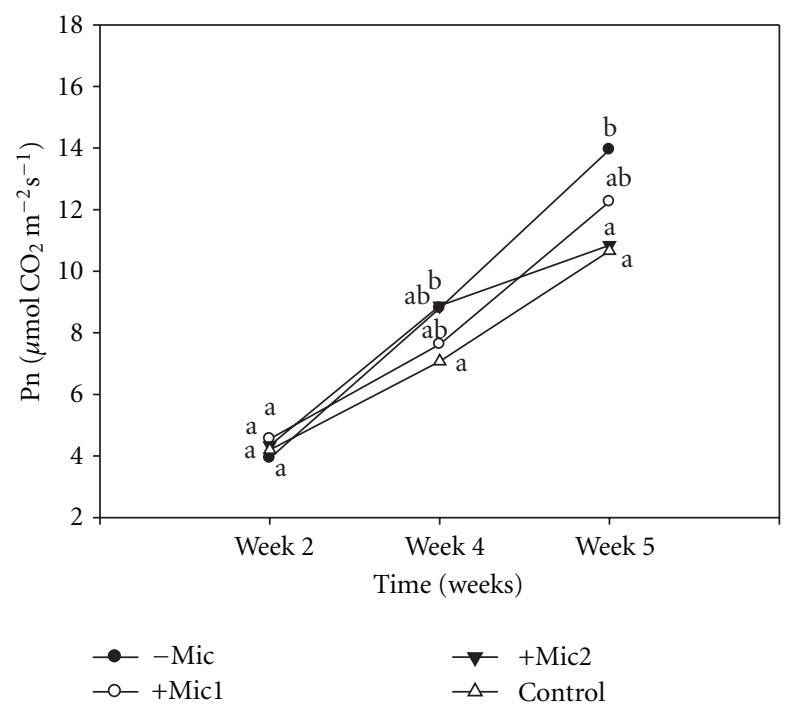

(c)

Figure 3: $P n$ changes observed at weeks 2, 4, and 5 of the experiment in papaya Maradol plants grown with or without mycorrhiza. (a) Pi $0 \mathrm{mM}$, (b) Pi $0.3 \mathrm{mM}$, (c) Pi $0.6 \mathrm{mM}$. Control group was grown without AM fungi supplied, with Pi $1.0 \mathrm{mM}$. Data are means \pm SD $(n=5)$. Values with the same letter for treatments within each week, had no statistical difference (Tukey 95\%).

grow in good conditions, the photosynthetic efficiency has values about 0.83 but when an environmental factor is stressing them, the PSII efficiency is affected and the $\mathrm{F}_{\mathrm{V}} / \mathrm{F}_{\mathrm{M}}$ values fall [23]. In the present work, the $\mathrm{F}_{\mathrm{V}} / \mathrm{F}_{\mathrm{M}}$ values suggest that $\mathrm{AM}$ association reduced the damage of Pi stress on the maximum efficiency of PSII.

On the other hand, it has been reported that AM colonization improves $P n$ in young leaves but this is not necessarily translated into an increased dry weight [24] as the gained carbon could be used to maintain the symbiosis in addition to growth [25]. In the present work, the AM colonization benefit was reduced when papaya Maradol was fertilized with Pi $0.6 \mathrm{mM}$. This may be because, as it has been proposed by Olsson et al. [26], under conditions of sufficient $\mathrm{P}$ the root reduced the carbon flow to the fungus, therefore the response of AM association to $\mathrm{P}$ sufficient conditions would depend on the P status of the colonized root.
Our results show that even without supply of added Pi in HS (0 mM), papaya Maradol plants associated with the AM fungus $G$. intraradices had higher leaf $\mathrm{P}$ content than their - Mic counterparts. It has been shown that the Pi taken up by AM fungus G. intraradices is delivered almost totally to the plant, contributing significantly to the plants P take-up capacity from the soil [15].

The higher $\mathrm{P}$ content reported in the present work in + Mic plants compared to those at -Mic plants in the absence of supplied Pi through the $\mathrm{HS}(\mathrm{Pi}=0 \mathrm{mM})$ may be explained by the fact that the mycorrhizal association enabled plants to take up more Pi from that still present in the substrate from the pretreatment Pi supply (see Section 2).

The $\mathrm{P}$ foliar concentrations found in our experiments are in agreement with other reports [21]. The total P reported here is on the range of those reported for other plant species $[7,8,27]$. The ranges of $\mathrm{P}$ content reported through the 


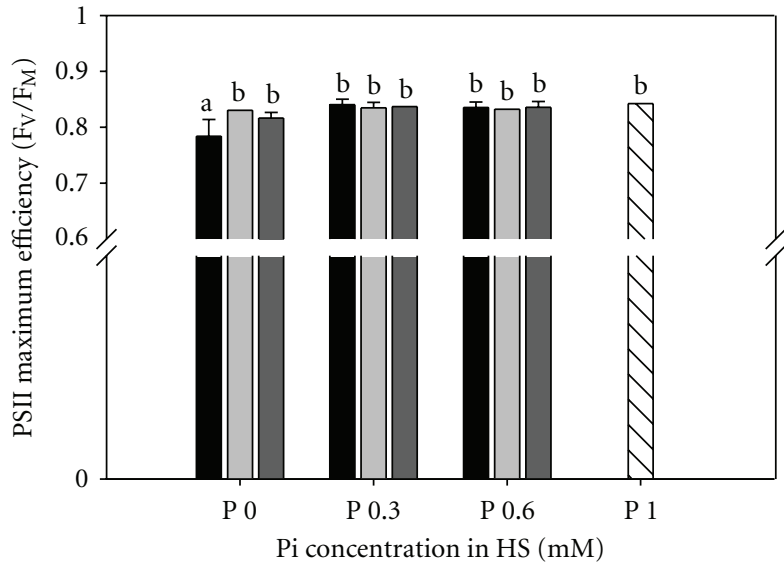

(a)

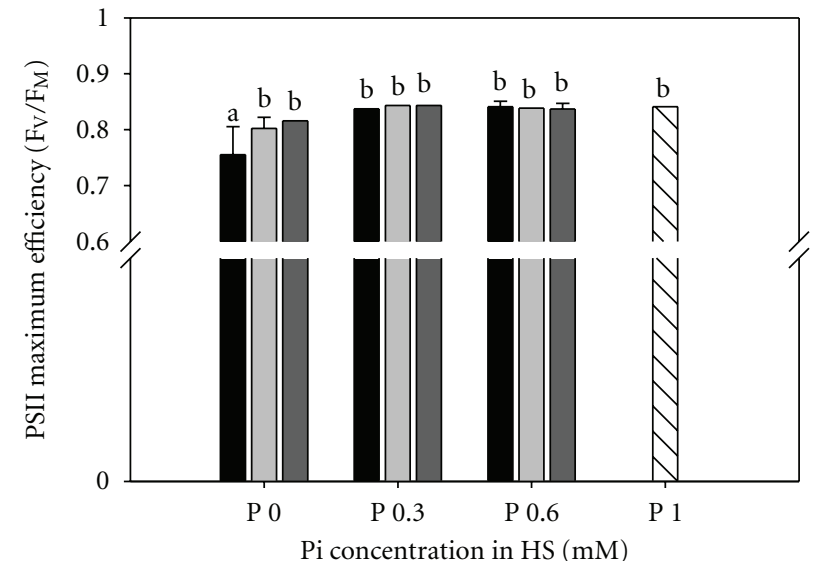

(b)

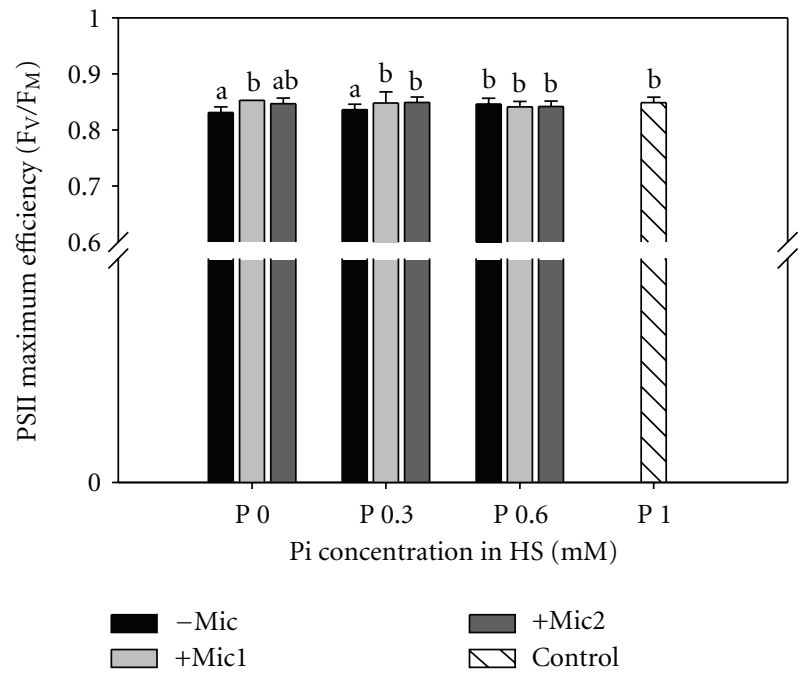

(c)

Figure 4: Chlorophyll fluorescence $\left(\mathrm{F}_{\mathrm{V}} / \mathrm{F}_{\mathrm{M}}\right)$ found at week five of the experiment in papaya Maradol plants grown with or without mycorrhiza with (a) Pi $0 \mathrm{mM}$, (b) Pi $0.3 \mathrm{mM}$, and (c) $0.6 \mathrm{Pi} \mathrm{mM}$. Control group was grown without AM fungi supplied, with Pi $1.0 \mathrm{mM}$. Data are means $\pm \mathrm{SD}(n=5)$. Values with the same letter for treatments within each week had no statistical difference (Tukey $95 \%)$.

literature may be the result of the fact that in every case the $\mathrm{Pi}$ availability of the substrate is different or because the $\mathrm{P}$ uptake is different not as a result of the AM colonization intensity but perhaps because of differences in the expression of genes involved in Pi transport in the different species [7].

The AM colonization intensity in a plant, depends on the AM fungi species to which the plant is associated [15]. Although, it has been reported that sometimes the mineral fertilization is not decreasing the AM colonization [19, 28], in most cases it has been suggested that increased supply of Pi decreases the AM colonization in crops like wheat or pea [29], Zea mays and Cucurbita pepo [30]. In the present work, colonization decreased as the $\mathrm{Pi}$ concentration was reduced but at concentrations as high as $0.6 \mathrm{mM} \mathrm{Pi}$, AM colonization was not totally inhibited, particularly with +Mic2 (Table 1).

It is suggested that under the experimental conditions of this work, the papaya Maradol efficiency to take up Pi was increased when it was associated with $G$. intraradices resulting in higher $P n$ and dry weight than their noninoculated counterparts grown at the same Pi condition. Furthermore, $P n$ and $\mathrm{F}_{\mathrm{V}} / \mathrm{F}_{\mathrm{M}}$ values found in +MIC plants at low $\mathrm{Pi}$ levels were closer to those of control plants grown without Pi limitation. However, the Pearson's coefficient shows low correlation between $\mathrm{Pn}$ and leaves $\mathrm{P}$ content $(r=0.52$ and 0.6 for + Mic1 and + Mic2, resp.) while the correlation coefficient between dry weight and leaves $\mathrm{P}$ content was high $(r=0.96)$ with the two strains of $G$. intraradices suggesting that AM association allowed more plant growth but part of photosynthates resulting from the increased $P n$ were used to maintain the association.

From our results, it can be concluded that growth and $P n$ in papaya Maradol plants decreased strongly under low Pi supply. However, the AM association with G. intraradices contributed to reduce the impact of the Pi scarcity on these parameters. On the other hand, it is suggested that the larger dry weight of AM plants, especially when Pi was not added in HS, was related to a better efficiency to take up $\mathrm{Pi}$ from their substrate. Finally, and despite 


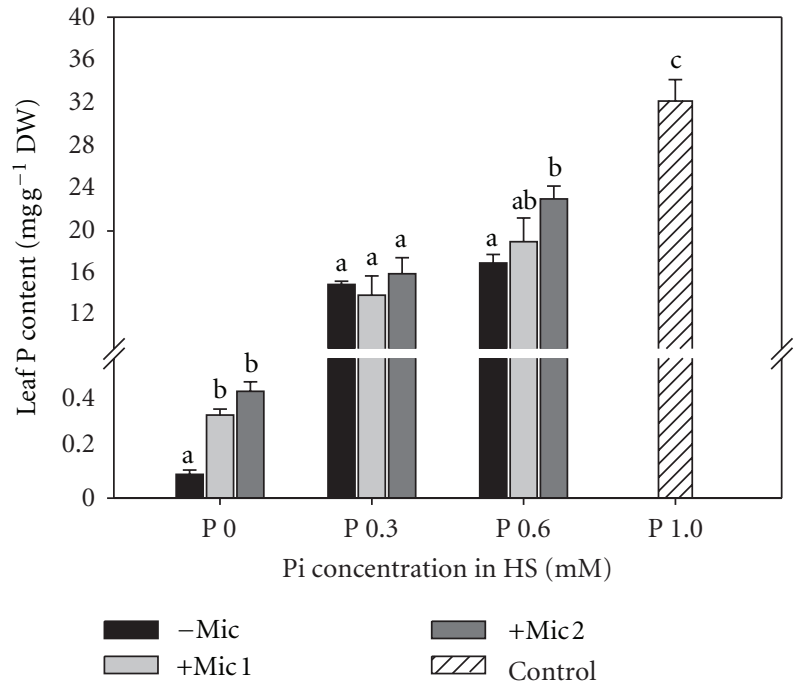

Figure 5: Total leaf P content found at week 5 of the experiment, in papaya Maradol plants grown with or without mycorrhiza and treated with Pi $0 \mathrm{mM}$, Pi $0.3 \mathrm{mM}$, and Pi $0.6 \mathrm{mM}$. Control plants were grown without mycorrhiza but treated with Pi $1 \mathrm{mM}$. Data are means $\pm \mathrm{SD}(n=5)$. Values with the same letter for treatments within each Pi concentration had no statistical difference (Tukey $95 \%)$.

the fact that AM association enhanced uptake of $\mathrm{Pi}$ and increased $\mathrm{Pn}$, the lower correlation between them suggests that some photosynthates could had been used to maintain the symbiosis.

\section{Acknowledgments}

YNG was holder of a PROMEP scholarship from the Universidad Autónoma de Tlaxcala. The authors are grateful to Dra Laura Hernández Terrones and Melina Soto (CICYCEA, Quintana Roo, México and to Dr Enrique Sauri (ITM, Yucatán, México) for performing the leaf $\mathrm{P}$ content evaluations and providing expert advice and to Dr. Alejandro Alarcón (Colegio de Postgraduados, Montecillo, México) for revising the paper.

\section{References}

[1] B. S. Ripley, S. P. Redfern, and J. Dames, "Quantification of the photosynthetic performance of phosphorus-deficient Sorghum by means of chlorophyll-a fluorescence kinetics," South African Journal of Science, vol. 100, no. 11-12, pp. 615618, 2004.

[2] J. Jacob and D. W. Lawlor, "Stomatal and mesophyll limitations of photosynthesis in phosphate deficient sunflower, maize and wheat plants," Journal of Experimental Botany, vol. 42, no. 8, pp. 1003-1011, 1991.

[3] H. Marschner, Mineral Nutrition of Higher Plants, Academic Press, San Diego, Calif, USA, 1995.

[4] K. G. Raghothama, "Phosphate acquisition," Annual Review of Plant Biology, vol. 50, pp. 665-693, 1999.

[5] D. P. Schachtman, R. J. Reid, and S. M. Ayling, "Phosphorus uptake by plants: from soil to cell," Plant Physiology, vol. 116, no. 2, pp. 447-453, 1998.
[6] S. E. Smith and D. J. Read, "Uptake, translocation and transfer of nutrients in mycorrhizal symbioses," in Mycorrhizal Symbiosis, S. E. Smith and J. D. Read, Eds., pp. 379-308, Academic Press, New York, NY, USA, 1990.

[7] S. Ravnskov and I. Jakobsen, "Functional compatibility in arbuscular mycorrhizas measured as hyphal $\mathrm{P}$ transport to the plant," New Phytologist, vol. 129, no. 4, pp. 611-618, 1995.

[8] S. H. Burleigh, T. Cavagnaro, and I. Jakobsen, "Functional diversity of arbuscular mycorrhizas extends to the expression of plant genes involved in P nutrition," Journal of Experimental Botany, vol. 53, no. 374, pp. 1593-1601, 2002.

[9] G. Al-Karaki, B. McMichael, and J. Zak, "Field response of wheat to arbuscular mycorrhizal fungi and drought stress," Mycorrhiza, vol. 14, no. 4, pp. 263-269, 2004.

[10] P. E. Mortimer, E. Archer, and A. J. Valentine, "Mycorrhizal $\mathrm{C}$ costs and nutritional benefits in developing grapevines," Mycorrhiza, vol. 15, no. 3, pp. 159-165, 2005.

[11] A. Alarcón, F. T. Davies, J. N. Egilla, T. C. Fox, A. A. Estrada-Luna, and R. Ferrera-Cerrato, "Short term effects of Gloms claroideum and Azospirillum brasilense on growth and root acid phosphatase activity of Carica papaya L. under phosphorus stress," Revista Latinoamericana de Microbiologia, vol. 44, no. 1, pp. 31-37, 2002.

[12] G. Bohrer, V. Kagan-Zur, N. Roth-Bejerano, D. Ward, G. Beck, and E. Bonifacio, "Effects of different Kalahari-desert VA mycorrhizal communities on mineral acquisition and depletion from the soil by host plants," Journal of Arid Environments, vol. 55, no. 2, pp. 193-208, 2003.

[13] A. V. Trindade, J. O. Siquiera, and P. F. de Almeida, "Dependencia micorrízica de variedades comerciais de mamoeiro," Pesquisa Agropecuária Brasileira, vol. 36, pp. 1485-1494, 2001.

[14] C. A. Martin and J. C. Stutz, "Interactive effects of temperature and arbuscular mycorrhizal fungi on growth, $\mathrm{P}$ uptake and root respiration of Capsicum annuum L," Mycorrhiza, vol. 14, no. 4, pp. 241-244, 2004.

[15] S. E. Smith, F. A. Smith, and I. Jakobsen, "Functional diversity in arbuscular mycorrhizal (AM) symbioses: the contribution of the mycorrhizal P uptake pathway is not correlated with mycorrhizal responses in growth or total P uptake," New Phytologist, vol. 162, no. 2, pp. 511-524, 2004.

[16] D. R. Hoagland and H. I. Arnon, The Water-Culture Method for Growing Plants without Soil, vol. 347, California Experimental Agriculture Station Circular, Berkeley, Claif, USA, 1950.

[17] T. Hoffmann, C. Kutter, and J. M. Santamaría, "Capacity of Salvinia minima baker to tolerate and accumulate As and $\mathrm{Pb}$," Engineering in Life Sciences, vol. 4, no. 1, pp. 61-65, 2004.

[18] J. M. Phillips and D. S. Hayman, "Improved procedures for clearing roots and staining parasitic and vesicular-arbuscular mycorrhizal fungi for rapid assessment of infection," Transactions of the British Mycological Society, vol. 55, pp. 158-161, 1970.

[19] M. P. Sharma and A. Adholeya, "Effect of arbuscular mycorrhizal fungi and phosphorus fertilization on the post vitro growth and yield of micropropagated strawberry grown in a sandy loam soil," Canadian Journal of Botany, vol. 82, no. 3, pp. 322-328, 2004.

[20] T. S. L. Lau, E. Eno, G. Goldstein, C. Smith, and D. A. Christopher, "Ambient levels of UV-B in Hawaii combined with nutrient deficiency decrease photosynthesis in near-isogenic maize lines varying in leaf flavonoids: flavonoids decrease photoinhibition in plants exposed to UV-B," Photosynthetica, vol. 44, no. 3, pp. 394-403, 2006.

[21] I. M. Rao and N. Terry, "Leaf phosphate status, photosynthesis, and carbon partitioning in sugar beet. IV. Changes 
with time following increased supply of phosphate to lowphosphate plants," Plant Physiology, vol. 107, no. 4, pp. 13131321, 1995.

[22] E. Epstein and A. J. Bloom, Mineral Nutrition of Plants: Principles and Perspectives, Sinauer Associates, Sunderland, Mass, USA, 2004.

[23] G. H. Krause and E. Weis, "Chlorophyll fluorescence and photosynthesis: the basics," Annual Review of Plant Physiology and Plant Molecular Biology, vol. 42, no. 1, pp. 313-349, 1991.

[24] D. P. Wright, J. D. Scholes, and D. J. Read, "Effects of VA mycorrhizal colonization on photosynthesis and biomass production of Trifolium repens L," Plant, Cell and Environment, vol. 21, no. 2, pp. 209-216, 1998.

[25] D. P. Wright, D. J. Read, and J. D. Scholes, "Mycorrhizal sink strength influences whole plant carbon balance of Trifolium repens L," Plant, Cell and Environment, vol. 21, no. 9, pp. 881$891,1998$.

[26] P. A. Olsson, I. M. Van Aarle, W. G. Allaway, A. E. Ashford, and H. Rouhier, "Phosphorus effects on metabolic processes in monoxenic arbuscular mycorrhiza cultures," Plant Physiology, vol. 130, no. 3, pp. 1162-1171, 2002.

[27] G. Cruz-Flores, S. Avilés Marín, and J. C. Cortés Castelán, "Estudio de adaptabilidad del triticale a diferentes dosis de calcio y fósforo en andisoles," Terra, vol. 16, no. 1, pp. 63-69, 1998.

[28] M. Gryndler, J. Larsen, H. Hrselová, V. Rezácová, H. Gryndlerová, and J. Kubát, "Organic and mineral fertilization, respectively, increase and decrease the development of external mycelium of arbuscular mycorrhizal fungi in a long-term field experiment," Mycorrhiza, vol. 16, no. 3, pp. 159-166, 2006.

[29] M. H. Ryan and J. F. Angus, "Arbuscular mycorrhizae in wheat and field pea crops on a low P soil: increased Zn-uptake but no increase in P-uptake or yield," Plant and Soil, vol. 250, no. 2, pp. 225-239, 2003.

[30] M. S. Schroeder and D. P. Janos, "Plant growth, phosphorus nutrition, and root morphological responses to arbuscular mycorrhizas, phosphorus fertilization, and intraspecific density," Mycorrhiza, vol. 15, no. 3, pp. 203-216, 2005. 

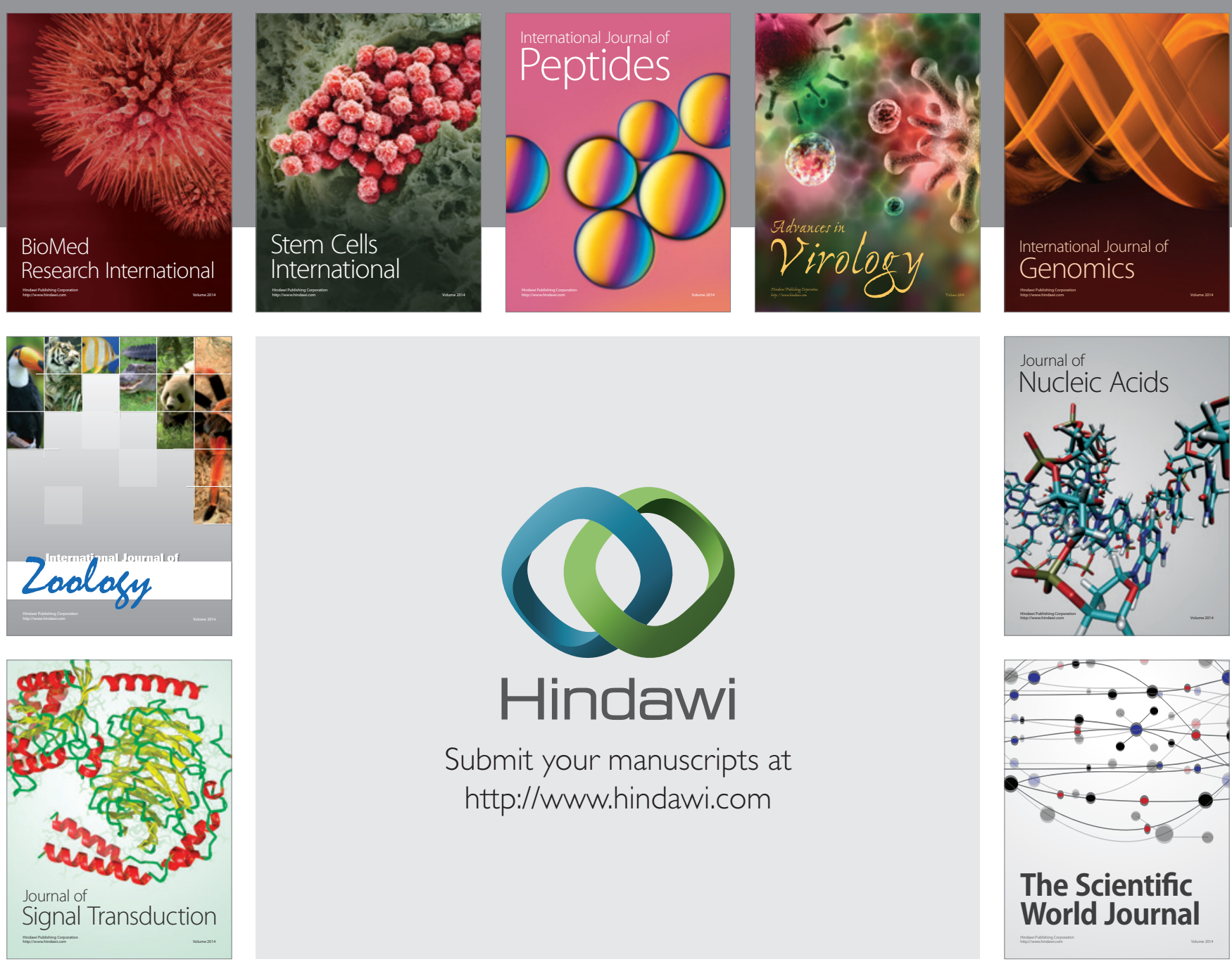

Submit your manuscripts at

http://www.hindawi.com
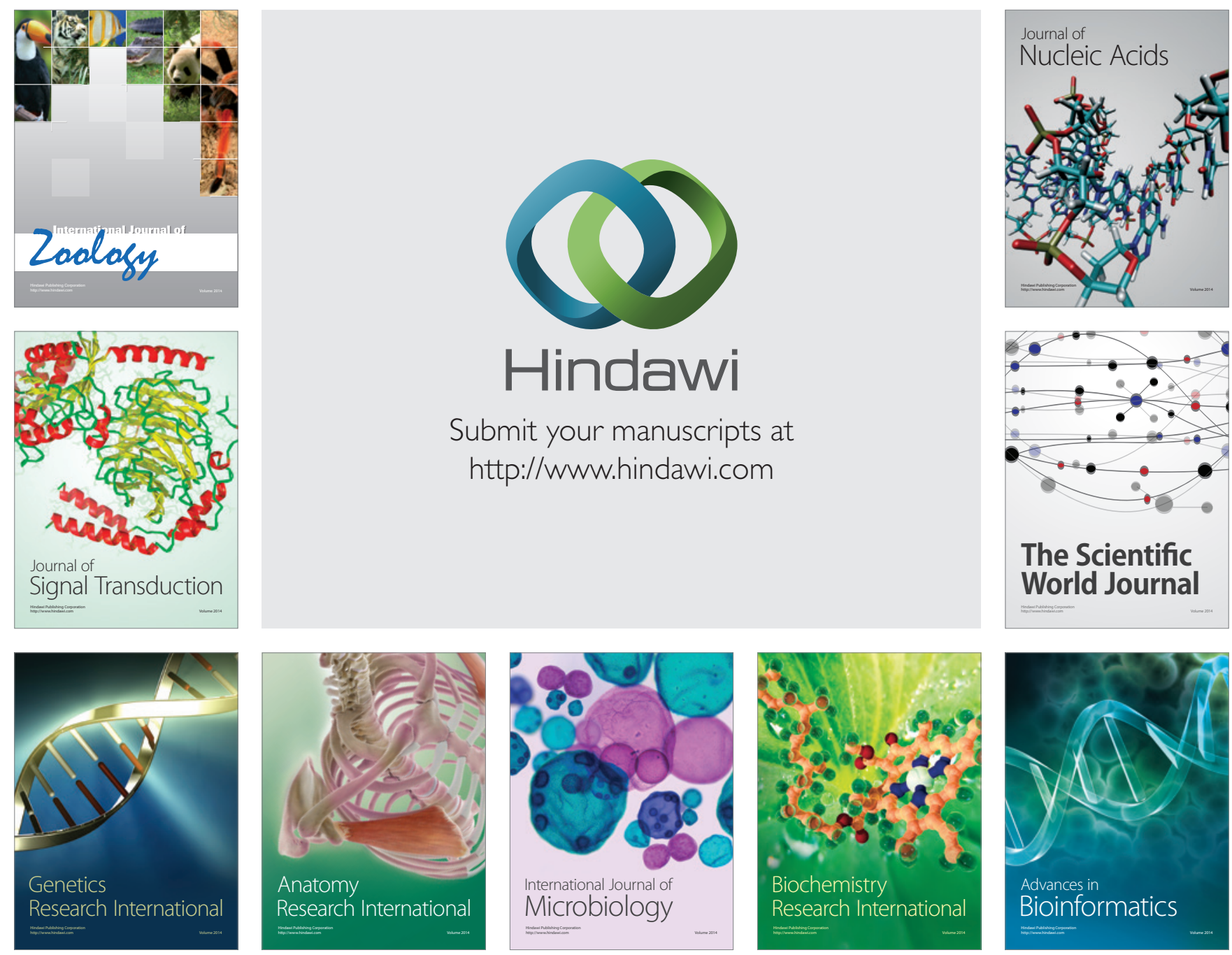

The Scientific World Journal
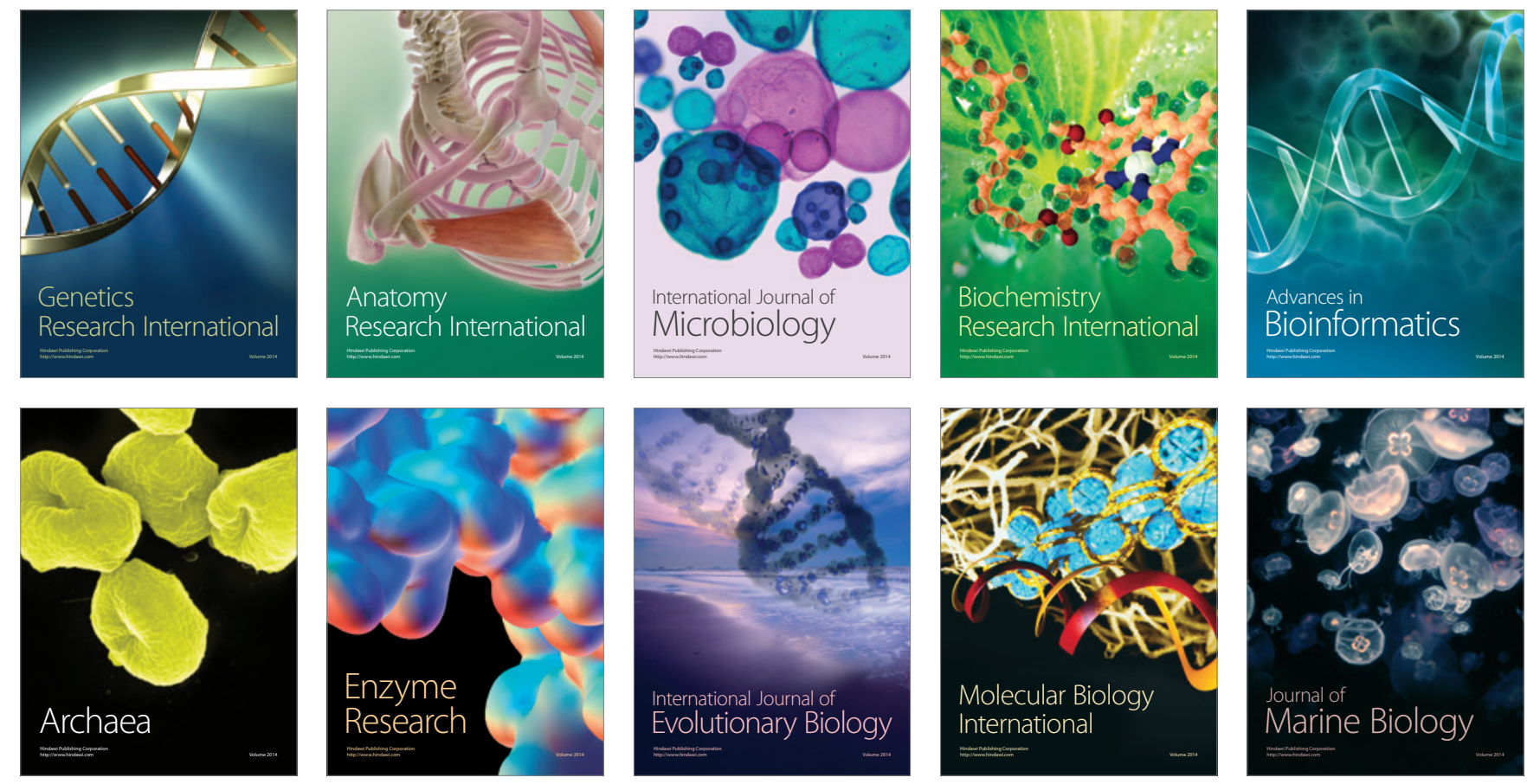